\title{
EL ESTADO, LA CONSTITUCIÓN Y LA ECONOMÍA DE MERCADO
}

SONIA PATRICIA CORTÉS ZAMBRANO. Abogada Universidad Santo Tomás, Especialista en Derecho Constitucional y Derecho Parlamentario de la Universidad Externado de Colombia y Universidad Autónoma de Madrid, Estudiante de Doctorado en Derecho, Universidad Externado de Colombia, Docente Investigadora del Centro de Investigaciones Socio Jurídicas Francisco de Vitoria y Coordinadora del Semillero de Derecho Público de la Universidad Santo Tomás.

E mail: Sonetzka@hotmail.com

Fecha de entrega: Octubre 23 de 2009

Fecha de Aprobación: Noviembre 09 de 2009

\section{RESUMEN}

Los derechos económicos constituyen hoy por hoy, la piedra angular en el desarrollo social, cultural y político de un país. Se pretende a partir de ellos dar eficacia al principio de igualdad, generar oportunidades de desarrollo, estimular a la sociedad para la puesta en marcha de la solidaridad, y entre muchos otros objetivos, generar progreso en el país. El Estado Colombiano, tiene como deber constitucional, promover la actividad económica, en procura del cumplimiento de sus fines sociales. Este artículo, esboza en que forma el Estado, en cumplimiento de sus fines constitucionales, participa con papel protagónico, en el desarrollo y dirección de la actividad económica del país, y su deber de defensa de la democracia.

\section{SUMMARY}

The economic rights constitute today per today, the angular stone in the social, cultural and political development of a country. It is sought starting from them to give effectiveness at the beginning of equality, to generate development opportunities, to stimulate to the society for the setting in march of the solidarity, and among many other objectives, to generate progress in the country. The Colombian State, has as constitutional duty, to promote the economic activity, in it offers of the compliance of its social ends. This article, sketches in that forms the State, in compliance of its 


\section{REVISTA VIRTUAL VIA INVENIENDI ET IUDICANDI \\ "CAMINO DEL HALLAZGO Y DEL JUICIO"}

http://viei.usta.edu.co/E-MAIL: revistainveniendi@usantotomas.edu.co

constitutional ends, it participates with protagonist paper, in the development and directión of the economic activity and the democracy.

\section{PALABRAS CLAVES:}

Constitución Económica, Estado Social de Derecho, Dirección de la Economía, Economía de Mercado, Globalizacón, Democracia.

\section{KEY WORDS:}

Constitution Economic, Social State of Law, Direction of Economy, Market Economy, Globalization, Democracy

Identificación del Artículo: Reflexión Académica.

\section{EL ESTADO, LA CONSTITUCIÓN Y LA ECONOMÍA DE MERCADO}

La reflexión sobre el derecho económico debe partir de nuestra Constitución, particularmente de los principios estructurales de orden político que se contiene en su artículo $1^{\circ}$.

Al igual que éste, existen en la Constitución múltiples disposiciones, referidas al modelo de Estado, que inciden sobre la actuación de la administración y del Estado y en general sobre la Economía. Es por esto que conviene recordar el sentido del Modelo de Estado Social de Derecho, las exigencias y problemas básicos que se plantean en la actualidad en la Administración Económica.

Es el factor económico, el que en buena medida determina las relaciones de poder, las relaciones sociales, y las relaciones nacionales e internacionales. Sin embargo, los acontecimientos históricos permiten verificar que el factor económico sitúa en una dinámica de privilegio al individuo, a la colectividad o al Estado, de acuerdo al momento histórico y la ideología política-económica.

El Estado tiene una posición de privilegio en la época del absolutismo monárquico, que identificaban al Estado con la persona del soberano. (MONTENEGRO 1997) 


\section{REVISTA VIRTUAL VIA INVENIENDI ET IUDICANDI \\ "CAMINO DEL HALLAZGO Y DEL JUICIO"}

http://viei.usta.edu.co/ E-MAIL: revistainveniendi@usantotomas.edu.co

En el individualismo, se privilegia al individuo; es la expresión de la "Democracia Liberal", que evidencia la prevalencia del individuo en la dinámica política, en el escenario de lo político. Es característico de esta tendencia, limitar al máximo la intervención del Estado, en todas las esferas de la vida social y particularmente en la económica.

El liberalismo tiene sus orígenes en el siglo XVII, en Inglaterra. Este demanda que en sus distintas corrientes doctrinarias el respeto por los intereses y derechos de los individuos y defiende los postulados de libre mercado y la ninguna o mínima intervención del Estado en la esfera económica de la sociedad.

El individualismo liberal, en sus dos aspectos, el económico y el político, destaca principio de igualdad, que gira en torno a la posibilidad de que todos los individuos puedan competir en el mercado en forma libre.

En la época moderna, por tanto surge la idea de conformar el Estado por acuerdo de todos los ciudadanos, libres e iguales ante la ley, siendo esta idea el resultado de la sed de libertad e igualdad que anima a los hombres tras siglos de dominación y abusos de las monarquías, amparadas en el poder igualmente absoluto de la iglesia (Echeverri 2002).

Por ello, las ideas revolucionarias de la llamada ilustración, desencadenaron acontecimientos que dieron lugar a la proclamación de escritos que contenían catálogos de derechos que eran considerados inherentes a la naturaleza humana y su eminente dignidad.

La Francia de la ilustración es el más claro ejemplo de una sociedad que dio rienda suelta al pensamiento individualista; que rechazaba el absolutismo del poder monárquico en cabeza de unos pocos, el rey y la nobleza que atentaba contra las libertades y los derechos del pueblo.

El Estado es debilitado como consecuencia de los ideales liberales de acuerdo a la celebre expresión de Condorcet "mientras menos se gobierne mejor". Pero la crisis social que se engendra a partir del desarrollo del capitalismo exigirá un papel más 


\section{REVISTA VIRTUAL VIA INVENIENDI ET IUDICANDI \\ "CAMINO DEL HALLAZGO Y DEL JUICIO"}

http://viei.usta.edu.co/E-MAIL: revistainveniendi@usantotomas.edu.co

activo del Estado como corrector de los desequilibrios sociales. El Estado representa una autoridad que es útil al individuo y que descansa en la legitimidad derivada de su concepción jurídico-política (Estado Nación) (Echeverri 2002).

Grandes pensadores, que enfrentaban las ideas liberales, como Marx, formularon el ideario socialista y comunista motivado en el propósito de contrarrestar los efectos funestos del liberalismo económico. Estas ideas, como lo expresa Montenegro (1997), ubican en la dinámica de privilegio a la colectividad, el individuo debe trabajar por la colectividad para hacerse acreedor a la justa parte que le corresponde. En esta ideología, la única propiedad respetable es la que cumple una función social.

Uno de los efectos más funestos del individualismo liberal fue el de propiciar la lucha de clases en una intensidad mayor que en cualquier otra época de la historia. Después de la segunda guerra mundial, se consolidaron en Europa formas de gobierno abiertamente opuestas a los principio del individualismo liberal. A partir de éstas resurge el poder del Estado como "Estado Bienestar" versus el "Estado Gendarme" del siglo XIX y en el cual es Estado se constituye en el garante del bienestar general de un orden social justo.

\section{ESTADO DE BIENESTAR}

El Estado de bienestar se fundamenta en la teoría keinesiana del Estado como instrumento de acción anticíclica, es decir, el Estado de bienestar se asume como un medio para conjurar la crisis del capitalismo verbigracia aumento de los consumos para lo cual se adelantan políticas de mejoramiento salarial y seguridad social (ECHEVERRI 2002). La teoría económica Keinesiana la adopta el Estado en momentos de crisis para neutralizar la caída económica su fundamento es:

- Garantía del empleo y

- Distribución equitativa de la riqueza. 


\section{REVISTA VIRTUAL VIA INVENIENDI ET IUDICANDI \\ "CAMINO DEL HALLAZGO Y DEL JUICIO"}

http://viei.usta.edu.co/ E-MAIL: revistainveniendi@usantotomas.edu.co

El Estado de Bienestar entra en crisis en los años sesentas y setentas, y entre las variadas causas están la necesidad de satisfacción de demandas sociales para generar lealtad social y política: Legitimidad, el propósito de bienestar es un propósito económico en donde a mayor necesidades satisfechas mayor demanda de necesidades por satisfacer, lo cual agota al Estado y lo hace siempre insuficiente para el cubrimiento de necesidades sociales crecientes. Se incrementan las demandas contra el Estado por incumplimiento en sus compromisos sociales por las minorías, lo cual devela que la lealtad ciudadana hacia el Estado no es real. La sociedad es generadora de necesidades, siempre está ante una constante insatisfacción que a su vez genera movimientos sociales contra los Estados.

\section{ESTADO SOCIAL DE DERECHO}

El Estado Social de Derecho aunque es un Estado intervencionista en lo económico y social, para procurar niveles de bienestar general no tiene identidad con el Estado de Bienestar o Welfare State. El Estado Social de Derecho responde a un concepto ético: procurar la igualdad de oportunidades con respecto al acceso a los bienes básicos, para la subsistencia del ser humano en razón de su dignidad como persona. (ECHEVERRI 2002).

La expresión Estado Social de Derecho, arranca del constitucionalismo alemán (Ley Fundamental de BONN 1949) posterior a la primera guerra mundial, desarrollado en Europa entre los años 1920 a 1970. A partir de la década de los setenta del siglo $\mathrm{XX}$, al triunfar las ideas neoliberales, se empieza a cuestionar el modelo de Estado Social y se comienza su desmonte en las democracias occidentales.

Con todo, el auge del Estado bienestar y del Estado social se cumple durante el periodo 1945-1973, y se presenta como un sistema social desarrollado en las democracias capitalistas industrializadas. Sus rasgos característicos fueron:

1. Intervención estatal en la economía para mantener el pleno empleo o garantizar un alto nivel de ocupación. 


\section{REVISTA VIRTUAL VIA INVENIENDI ET IUDICANDI \\ "CAMINO DEL HALLAZGO Y DEL JUICIO"}

http://viei.usta.edu.co/ E-MAIL: revistainveniendi@usantotomas.edu.co

2. Provisión pública de una serie de servicios sociales, en función del cubrimiento de las necesidades humanas básicas de los ciudadanos en una sociedad compleja y cambiante (educación, salud, asistencia sanitaria, pensiones y vivienda), esto es, proveer la seguridad social en su sentido más amplio.

3. Responsabilidad estatal en el mantenimiento de un nivel mínimo de vida, entendido como su derecho social y no como caridad pública; como un problema de responsabilidad colectiva hacia todos los ciudadanos de una comunidad nacional moderna y democrática.

En la década de los cuarenta y setenta el Estado, por tanto, se constituye como el máximo garante y proveedor del bienestar colectivo.

El Modelo de Estado Social de Derecho, que entra en crisis a mediados de los años 70 `s es asumido en la Constitución de 1991, entre cuyos valores fundamentales se propugna por la igualdad, principios rectores de la política social y económica y enumerando los derechos del ciudadano y las obligaciones sociales y económicas del Estado (protección social, económica y jurídica de la familia, el deporte, el empleo, la salud, la cultura, el medio ambiente, la vivienda digna, a la tercera edad, etc.)

Las notas definitorias de "Estado Social" son nociones que se estructuran en expresiva correspondencia con los valores superiores de libertad, justicia, igualdad y pluralismo político, así como con las disposiciones fundamentales y principios constitucionales como la dignidad de la persona y el libre ejercicio de la personalidad.

Todo lo anterior puede verificarse al revisar la Jurisprudencia Constitucional Colombiana, en las líneas que perfilan el concepto de Estado Social, en relación con la trascendencia que en la interpretación de la Constitución han adquirido el derecho a la igualdad no solo como derecho fundamental individual, sino como principio constitucional y criterio de valoración de la constitucionalidad de las leyes. 
REVISTA VIRTUAL VIA INVENIENDI ET IUDICANDI

"CAMINO DEL HALLAZGO Y DEL JUICIO"

http://viei.usta.edu.co/ E-MAIL: revistainveniendi@usantotomas.edu.co

(T-505 de 1992, T-067 de 1998, T-542 de 1992, T-401 de 1994 y la SU-337 DE 1999)

\section{LA CONSTITUCIÓN Y EL MODELO ECONÓMICO EN COLOMBIA}

La Constitución es normativa, en cuanto establece límites normativos a la acción de los poderes públicos, y valorativa porque consagra principios y valores, pero es abierta, porque no constitucionaliza un modelo económico determinado, sino que admite modelos económicos diversos (UPRIMNY 2007 p. 15).

Según su contenido la constitución es valorativa al consagrar un orden de valores a ser realizados, procedimental cuando consagra un marco de actuaciones para los poderes públicos y los particulares regulando instituciones y procedimientos y normativa ya que vincula al legislador y al ejecutivo, y consagra un mecanismo de protección de su supremacía.

Los países con regímenes constitucionales, poseen constituciones valorativas y normativas, cuyas disposiciones imponen límites a la política económica, lo cual no implica constitucionalizar un modelo económico, pero sí que la política económica, tenga algunas restricciones normativas.

Las relaciones entre constitución y economía parten de los derechos que en la primera se consagran, que tiene que ver con los derechos económicos de libertad y los derechos sociales de prestación. Todos los derechos constitucionales, implican para el Estado obligaciones de respeto, protección, garantía, y de satisfacción o cumplimiento. En el caso de los derechos sociales algunos tienen un contenido esencialmente prestacional y en el caso de las libertades económicas, algunas requieren esencialmente abstención y aquí se justifica las diferencias de grado entre éstos derechos.

Existen constituciones que institucionalizan un modelo económico, no solo estableciendo límites a la actuación del Estado, sino también programando la política económica, prefigurando los instrumentos para llegar a un estado de cosas 


\section{REVISTA VIRTUAL VIA INVENIENDI ET IUDICANDI \\ "CAMINO DEL HALLAZGO Y DEL JUICIO"}

http://viei.usta.edu.co/E-MAIL: revistainveniendi@usantotomas.edu.co

esperadas. Las Constituciones abiertas cuando a pesar de ser valorativas y normativas, establecen límites a las políticas económicas, e incluso estados de cosas esperadas, sin determinar los instrumentos para alcanzar propósitos, dan la posibilidad de utilizar políticas e instrumentos y medios diversos para alcanzar los objetivos deseados.

Lo claro es que en la medida en que la Constitución tenga fuerza normativa y reconozca derechos fundamentales, impone límites a la política económica.

La Constitución de 1991 de Colombia, es una constitución normativa valorativa de constitucionalismo social, en la medida que no solo reconoce derechos liberales, sino también derechos sociales y les da fuerza normativa, pero es una Constitución abierta, porque admite políticas económicas muy diversas para alcanzar esos derechos sociales. (UPRIMNY 2007).

\section{LA CONSTITUCIÓN ECONÓMICA Y LA ECONOMÍA DE MERCADO}

Se entiende por Constitución Económica, el conjunto de principios, criterios, valores y reglas fundamentales que presiden la vida económico-social de un país, según un orden que se encuentra reconocido en la Constitución. Hace parte de la estructura básica de la Constitución, enmarcada en el modelo de sociedad y la idea de Estado que se quiere garantizar.

Por Constitución económica se ha de entender el conjunto de normas básicas destinadas a proporcionar el marco jurídico fundamental para la estructura y funcionamiento de la actividad económica, o dicho de otro modo, para el orden y el proceso económico. GARCÍA PELAYO (1985).

La función de la Constitución económica no debe entenderse como un concepto de ruptura o de quiebra de la unidad constitucional. Debe por el contrario asumirse que sus preceptos operan como parte de la ley superior, sin crear un destinatario diferenciado. La determinación de la Validez de cualquier norma jurídica relacionada con aspectos económicos, no solo se establece a partir de su 


\section{REVISTA VIRTUAL VIA INVENIENDI ET IUDICANDI \\ "CAMINO DEL HALLAZGO Y DEL JUICIO"}

http://viei.usta.edu.co/E-MAIL: revistainveniendi@usantotomas.edu.co

conformidad o discrepancia con la Constitución Económica sino con la integridad de la Constitución Política.

La Constitución Económica expresa la relación interdependiente entre derecho y economía, entre libertad económica y libertad política, como expresiones de una idea unitaria de libertad. La regulación jurídica de la libertad económica exige una estructura democrática de creación del derecho, y a su vez, una economía de libre circulación es el fundamento ideal de un orden político democrático.

Fundamentalmente hay dos sistemas posibles de organización social y económica: liberal y socialista.

LIBERAL: Es un sistema de economía de mercado presidido por la soberanía del consumidor, la libertad de precios, la libre competencia, el principio de beneficio y la libre decisión empresarial. Todo ello sobre la base de la propiedad privada de los medios de producción.

SOCIALISTA: Es un sistema de economía dirigida o de planificación central, presidido por las decisiones de la autoridad en base a las necesidades estimadas de los ciudadanos, bajo un régimen de precios controlados y remuneraciones tasadas, tanto para la empresa como para sus agentes. Todo ello sobre la base de la propiedad colectiva de los medios de producción.

Como modelos intermedios suele hablarse de los sistemas de economía mixta y economía social de mercado, en los que se combinan los dos sistemas de decisión (individual y estatal) y de propiedad (pública y privada). A este modelo corresponde la Constitución Colombiana.

Dentro de las normas básicas o fundamentales sobresalen dos categorías esenciales que permiten distinguir lo que $\mathrm{REICH}(1985)$ ha denominado la doble instrumentalidad del derecho en la economía y que consiste: de un lado, la que contempla instrumentos que autorizan la intervención del Estado en la Economía y de otro, la que pone límites a dicha intervención a través de postulados 


\section{REVISTA VIRTUAL VIA INVENIENDI ET IUDICANDI \\ "CAMINO DEL HALLAZGO Y DEL JUICIO"}

http://viei.usta.edu.co/E-MAIL: revistainveniendi@usantotomas.edu.co

constitucionales de derechos de naturaleza económica reconocidos a los particulares.

La Constitución Económica es una necesidad, un componente propio de las constituciones liberales de los Estados Democráticos y existe en virtud de la exigencia de definir quien tiene el poder de configuración de la actividad económica, dentro de qué límites y de qué forma.

\section{Neutralidad y rigidez de la Constitución Económica}

Es una garantía que se activa a favor del principio democrático. Se relaciona directamente con el papel del legislador en la fijación de los contenidos normativos del sistema económico del Estado, papel que procede del principio de legalidad que caracteriza las intervenciones de este y de las personas. Con todo, esa relación intensa entre representación y reglas económicas, no se desliga de las normas que integran la Constitución Económica ni los demás preceptos de la norma superior.

En la Sentencia C- 074 DE 1993 de la Corte Constitucional y como un obiter dictum, se observa: "La constitución Nacional de corte finalista o teleológico recoge la doctrina constitucional contemporánea y consagra un Estado interventor a través de un conjunto sistemático de disposiciones jurídicas destinadas a la realización de un orden económico y social justo, dentro del marco del Estado Social de Derecho". De esta nueva fisonomía del Estado se destacan tres elementos esenciales relacionados con:

1. Los valores de la igualdad y la solidaridad y los distintos valores consagrados en la Constitución.

2. Los instrumentos de intervención en la esfera social y económica de los particulares.

3. Los instrumentos de control sobre la gestión pública.

Con base en ellos se concluye abiertamente: "No se trata entonces de un texto neutro que permita la aplicación de cualquier modelo económico, pues las 


\section{REVISTA VIRTUAL VIA INVENIENDI ET IUDICANDI \\ "CAMINO DEL HALLAZGO Y DEL JUICIO"}

http://viei.usta.edu.co/E-MAIL: revistainveniendi@usantotomas.edu.co

instancias de decisión política deben de una parte respetar los límites impuestos por el conjunto de derechos y de otra operar conforme a los valores y principios rectores que la Constitución consagra, así como procurar la plena realización de los derechos fundamentales." Señala además: "Ahora bien es cierto que la Carta crea un marco general de regulación económica pero mal podría un texto -que pregona como fundamental el principio de la democracia- constitucionalizar un modelo económico restringido, rígido, inamovible, que tuviera como efecto legitimar exclusivamente una ideología o partido y vetar todas aquellas que le fueren contrarias. El principio democrático supone la idea de alternación y ésta solo se cumple si es posible que se debata en el panorama político con ideas y doctrinas diferentes a partir de las cuales la voluntad popular, representada en las urnas elija la que a su juicio desarrolle de mejor manera los conceptos de justicia que encierra la Carta Política."

Se sienta aquí la doctrina de las "Tensiones Recíprocas" de los principios constitucionales y la democracia, con particular significación en materia económica que, dicho sea de paso, devela la tensión entre el Estado de Derecho y Estado Social de Derecho. (CORREA 2008)

\section{Aparente contraposición de principios constitucionales}

\begin{tabular}{|l|l|l|}
\hline $\begin{array}{l}\text { Derecho a la Propiedad y libre } \\
\text { transmisión de la misma, art. 58, 61 y } \\
332\end{array}$ & $\begin{array}{l}\text { Función social de la propiedad, } \\
\text { subordinación de la propiedad al interés } \\
\text { general, art. 58 }\end{array}$ \\
\hline $\begin{array}{l}\text { Economía de Mercado y defensa de la } \\
\text { competencia, art. 333 }\end{array}$ & $\begin{array}{l}\text { La ley delimita el alcance de la libertad } \\
\text { económica, art. 333 }\end{array}$ \\
\hline $\begin{array}{l}\text { Libertad de empresa, art. 334 } \\
\text { (defensa de la }\end{array}$ & $\begin{array}{l}\text { La dirección general de la Economía a } \\
\text { cargo del Estado, art. 334 }\end{array}$ \\
\hline $\begin{array}{l}\text { Libre asociación al derecho a la huelga, art. } \\
\text { productividad), art. 38 }\end{array}$ & \\
\end{tabular}




\section{REVISTA VIRTUAL VIA INVENIENDI ET IUDICANDI \\ "CAMINO DEL HALLAZGO Y DEL JUICIO"}

http://viei.usta.edu.co/E-MAIL: revistainveniendi@usantotomas.edu.co

Esta aparente ambivalencia, se desprende del carácter abierto de la Constitución económica, que deja al liderazgo político en cada momento, la elección de variados modelos o formas de ordenar la vida económica y el mayor o menor protagonismo que se le fije al Estado, en materia económico-social.

\section{Economía Social de Mercado}

1. Es una vía distinta a la del liberalismo o la del socialismo, en la que se incluyen hoy la mayoría de los Estados Occidentales. En ella se consagra una economía de mercado basada en la libertad e iniciativa privadas, que admite ciertas intervenciones del Estado (lo cual garantiza una mínima cobertura de servicios a todos los ciudadanos) complementarias y compatibles con aquellas.

2. Llamado también de economía mixta, se combinan de forma asistemática, actuaciones privadas y estatales, las propiedades pública y privada, en diferentes medidas y proporciones, según las necesidades de cada momento.

La diferencia entre una y otra radica en el nivel de protagonismo del Estado.

Los Conceptos en los que puede basarse el modelo económico colombiano deben ser flexibles pero sin que se vicie su contenido esencial.

El derecho a la Propiedad tiene un contenido esencial mínimo. Se puede hablar de tipos de propiedad pero no se le puede dejar sin contenido, ya que si ello ocurriese el ciudadano quedaría dependiendo absolutamente del Estado y sus instituciones, imposibilitándose la economía de mercado.

La Economía de mercado, tiene un contenido esencial mínimo, no puede ser una "economía dirigida de mercado", y a la vez, ser "economía de mercado" libre y sin control del poder público. 


\section{REVISTA VIRTUAL VIA INVENIENDI ET IUDICANDI \\ "CAMINO DEL HALLAZGO Y DEL JUICIO"}

http://viei.usta.edu.co/ E-MAIL: revistainveniendi@usantotomas.edu.co

Por lo anterior, podría afirmarse que en el modelo económico apoyado en la Constitución, no caben todo tipo de medidas de intervención estatal, sino que caben medidas complementarias, conformes al sistema, ya sea para corregir comportamientos viciosos de la economía de mercado o para establecer una red de seguridad con servicios que no serían atendidos por el mercado, como la cultura o la salud.

\section{La Constitución como norma jurídica}

Los principios jurídicos constitucionales no son conceptos jurídicos controlables por un juez. Constituyen, ciertamente, formulaciones de orientación política; conceptos abiertos que no permiten interpretación por los cauces de una rigurosa lógica jurídica.

La neutralidad económica de la Constitución, se presenta como garantía a favor del principio democrático y hace referencia al papel que el legislador desempeña en la fijación de los contenidos normativos del sistema económico del Estado, aspecto que se fundamenta en el principio de Legalidad que garantiza las intervenciones en los derechos e instituciones de todo orden, incluidos los que corresponden a la Constitución Económica.

El valor de la constitución económica, como marco jurídico fundamental, para la definición de la libertad económica y de sus restantes elementos, es un criterio de análisis del derecho constitucional, útil para resolver el problema de desenvolvimiento económico de los particulares y del Estado; como condición material cada vez más relevante para concretar la eficacia o ineficacia del orden jurídico en general. La contribución de la Constitución Económica consiste en permitir una más clara interpretación de los derechos e instituciones que describen el ámbito económico, por su relevancia para la vida del ser humano y del propio Estado; una descripción más acabada de las bases económicas en las cuales se sustenta la totalidad del proyecto constitucional. 


\section{REVISTA VIRTUAL VIA INVENIENDI ET IUDICANDI \\ "CAMINO DEL HALLAZGO Y DEL JUICIO"}

http://viei.usta.edu.co/E-MAIL: revistainveniendi@usantotomas.edu.co

\section{Límites constitucionales a la política económica en Colombia}

El Control de constitucionalidad de la economía en Colombia es un control leve de razonabilidad, en la medida en que el juez está obligado a mirar únicamente si el objetivo que persigue una política es constitucionalmente admisible, y si el medio para lograrlo es potencialmente adecuado para alcanzar dicho propósito.

La Corte Constitucional reconoce que la Constitución le otorga al Congreso y al Ejecutivo, amplitud y libertad de intervenir en la economía y de configurar las políticas económicas, y por consiguiente el juez constitucional no debe admitir un juego de políticas cambiantes. En lo que tiene que ver con los derechos sociales, la constitución establece imperativos o deberes para las autoridades, orientadas a satisfacer esos derechos sociales. Pero la Constitución y la jurisprudencia admiten medios diversos para la realización de dichos derechos.

\section{LA ECONOMÍA DE MERCADO}

\section{Fundamento Constitucional}

La economía de mercado es el segundo principio estructural de la Constitución Económica, en la medida en que con el se representa el componente integrador de carácter libertario en el que reposan la totalidad de las cláusulas de ordenación de la economía al interior del Estado.

La economía de mercado es un supuesto de la ordenación económica constitucional en Colombia. Así junto con el reconocimiento de la propiedad privada (art. 58, 61 y 332 C.P.) y el trabajo como derecho de libertad y como deber (art. 25 y 26 C.P.), su incersión en la norma superior se hace palpable en el artículo 333 de la C.P., con la declaración de la iniciativa privada y de la actividad económica como libres, junto con el derecho a la libre competencia, la distinción de la empresa como base del desarrollo y la obligación del Estado de impedir que se obstruya o restrinja la libertad económica, referencias normativas que describen propiamente ese tipo de sistema económico competitivo y libertario. 


\section{REVISTA VIRTUAL VIA INVENIENDI ET IUDICANDI}

"CAMINO DEL HALLAZGO Y DEL JUICIO"

http://viei.usta.edu.co/ E-MAIL: revistainveniendi@usantotomas.edu.co

En Colombia la Jurisprudencia ha introducido la economía de mercado como pieza integrante y principal de ese conjunto de normas económicas de la Constitución. Por ejemplo, en la sentencia C-535 de 1997, dentro de las conclusiones por las cuales se considera inexequible la limitación que para la libertad de contratación (como expresión de la libre empresa) supone el pacto de exclusividad en los contratos de suministro cuando se suscriben con miras a restringir o a anular la competencia. Porque "la economía de mercado es un elemento constitutivo de la Constitución Económica de cuyo funcionamiento adecuado depende la eficiencia del sistema productivo y el bienestar de los consumidores". Bajo la misma lógica, en la sentencia c-524 de 1995, la Corte encuentra constitucional el autorizar la publicidad de productos nocivos para la salud (bebidas alcohólicas, tabaco, y cigarrillo), en la medida en que este tipo de promoción comercial se corresponde con la economía de mercado como sistema económico constitucional, dentro del cual se consagra la libertad de empresa.

\section{La Economía de Mercado y su implicación en el derecho público}

El sistema multilateral de mercado depende en todo del buen funcionamiento de las economías internas de cada país. Esto implica que cada país debe alcanzar unos estándares económicos que tiendan a la homogeneidad.

La idea se dirige a recalcar que si cada Estado estructurara los mecanismos, normas y organizaciones propias, atentas a sus necesidades particulares y que atiendan eficazmente a la manera como hoy se realizan las transacciones, el caos generado por estos procesos de integración económica no generarían el colapso al que se enfrentan muchos al no aceptar la necesidad de transformar las ideas primeras en que se funda el Derecho Público, particularmente en lo que tiene que ver con la transformación del Estado de cara al nuevo orden global.

Esta transformación le exige al Estado replantear los conceptos de legitimidad, democracia, Estado de Derecho y Estado Social, para que sin dejar de lado el cumplimiento de sus deberes, coordine la actividad del mercado de manera tal que sus efectos negativos puedan ser controlados e incluso prevenidos. 


\section{REVISTA VIRTUAL VIA INVENIENDI ET IUDICANDI \\ "CAMINO DEL HALLAZGO Y DEL JUICIO"}

http://viei.usta.edu.co/ E-MAIL: revistainveniendi@usantotomas.edu.co

Para el Banco Mundial, el fracaso de la economía de mercado en muchos de los países en vía de desarrollo se asocia con la carencia de instituciones adecuadas que permitan el desarrollo del modelo y uno de los factores dominantes en el acrecentamiento de la crisis es la corrupción.

La incertidumbre en las relaciones son las que generan comportamientos arbitrarios, y son las instituciones formales de origen estatal y las desarrolladas como producto de la actividad empresarial, las que den esta certeza, característica propia del Estado de Derecho a punto de la seguridad jurídica.

Existe un acuerdo en la necesidad de fortalecer los procesos democráticos, la estimulación del desarrollo económico y social, y promoción del fortalecimiento de la sociedad civil, pero la idea se estanca al encontrarse con la estructura tradicional de las instituciones estatales, las precarias modalidades de gestión del Estado, las inadecuadas políticas públicas y el anacronismo de algunos ordenamientos jurídicos (ANZOLA 2005) instituciones para una economía de mercado. Los retos del derecho público en: el estado reflexiones acerca de sus retos en el siglo XXI. Carlos Molina Editor Universidad del Rosario Bogotá 2005.

Ha surgido un nuevo tipo de ciudadano a partir de las transformaciones sociales y culturales desencadenadas por el impacto de la economía de mercado y la integración económica, la característica fundamental radica en la desconfianza en las instituciones del sistema democrático tradicional, debido a la incapacidad de responder a las necesidades actuales.

El sistema de partidos evidencia la crisis de representatividad, al igual de su deficiencia al actuar como vehículo de vinculación y su lejanía de la sociedad civil, deja su acción pública desprovista de relación efectiva con la ciudadanía, generando una relación política desestructurada frente a las decisiones gubernamentales. 


\section{REVISTA VIRTUAL VIA INVENIENDI ET IUDICANDI \\ "CAMINO DEL HALLAZGO Y DEL JUICIO"}

http://viei.usta.edu.co/ E-MAIL: revistainveniendi@usantotomas.edu.co

\section{LA ECONOMÍA DE MERCADO Y EL ESTADO SOCIAL DE DERECHO}

El reconocimiento de la noción de economía de mercado dependerá de la interpretación sistemática, de modo que sea posible descubrir la función específica que cumple como elemento constitucional y su delimitación a través de otras nociones constitucionales.

Ningún derecho, institución o competencia, puede ignorar al Estado Social de Derecho, en tanto definidor de la organización política, así como tampoco esta puede, puede constituirse sin tener en cuenta aquellas categorías jurídicas.

Las libertades económicas y las competencias de la Constitución económica se edifican sobre la columna que también en lo económico protege el principio de igualdad material, del mismo modo esa igualdad debe protegerse en consonancia con el tipo de libertad económica reconocida en la economía de mercado.

La interpretación sistemática constitucional, obliga a tener en cuenta el todo, sin dejar por fuera ninguno de los preceptos, bienes, intereses, garantías que rigen determinadas materias o asuntos. El significado de Estado Social de Derecho, no puede trazarse pues, desde la negación de la libertad económica, de la libre competencia, del derecho a la propiedad y de la protección a los derechos de los trabajadores, la seguridad social, la salud, el medio ambiente, la dignidad humana y el bienestar colectivo.

La noción de economía de mercado estructura, da forma y coherencia a los derechos y libertades económicas, a la intervención, a las garantías de protección y a la imposición de límites a la ordenación económica estatal. El sistema económico constitucional es efectivamente el de la economía de mercado con carácter social, comúnmente nominado como economía social de mercado, como expresión que adscribe al sistema económico de la Constitución, lo libre económico con lo social, a la vez que la aplicación, 


\section{REVISTA VIRTUAL VIA INVENIENDI ET IUDICANDI \\ "CAMINO DEL HALLAZGO Y DEL JUICIO"}

http://viei.usta.edu.co/E-MAIL: revistainveniendi@usantotomas.edu.co

también en el ámbito económico del principio de pro libertate, como supuesto que integra la noción de Estado Social de Derecho.

\section{Naturaleza jurídica del mercado en la Constitución}

ARAGÓN REYES (1995), señala que la consagración del modelo de economía social de mercado tiene como base el hecho de que el mercado se convierte en una garantía institucional, en el que la libertad resulta atemperada por las exigencias de la igualdad.

La economía descansa en la institución de mercado, es decir que se basa en el libre juego de la oferta y la demanda, de los intereses de los dadores de bienes en el mercado y de los tomadores de bienes o consumidores, que actúan en el proceso productivo.

La noción de mercado, como bien jurídico constitucional sobre el cual reposa, si no la totalidad del sistema económico si su principio de actuación, la definición de la regla general de aplicación lo mismo que el fundamento de la libertad de empresa.

Es en el mercado donde se concreta la primera opción del constituyente para realizar el bienestar general en la medida que se trata del conjunto de beneficios colectivos. Es el espacio por tanto que mejor facilita y hace posible el ideal de justicia diseñado por la constitución. El mercado es entonces el instrumento para la libertad y la igualdad, para la justicia y la pluralidad, para el trabajo y la solidaridad, para la dignidad de la persona y el interés general. De allí, la importancia del requerimiento de su salvaguarda, de allí que el Estado Social de Derecho se sirva de él y sea permeable a su lógica; de allí que se reconozca su entidad constitucional.

\section{Elementos y Principios de la Economía de Mercado}

En la constitución de 1991, se ha consagrado, dentro de los distintos modelos de organización del mercado, aquel que privilegia la libertad y la concurrencia leal, 


\section{REVISTA VIRTUAL VIA INVENIENDI ET IUDICANDI \\ "CAMINO DEL HALLAZGO Y DEL JUICIO"}

http://viei.usta.edu.co/E-MAIL: revistainveniendi@usantotomas.edu.co

como forma que mejor promueve los intereses de los consumidores a la vez que el funcionamiento eficiente de los diferentes mercados.

La sentencia C-535 de 1997, define como elementos del mercado:

1. La libre iniciativa privada (libertad de empresa)

2. Libertad de organización de los factores de producción, que incluye la libertad contractual como facultad del sujeto económico libre

3. Concesión de poderosos instrumentos de intervención en cabeza del Estado, que le permiten sancionar concentraciones y abusos, ya sea mediante acciones de corrección, compensación o, en casos extremos, la sustitución completa de los mecanismos del mercado.

Entonces los elementos que integran el contenido iusfundamental de la economía de mercado son:

1. Los principios y derechos económico sociales

2. El principio pro libertate

3. El Principio de la libre competencia

4. La descentralización y la desconcentración

5. La intervención del Estado

6. La unidad del mercado

7. El carácter cualitativo y cuantitativo de los objetivos del sistema.

\section{El principio pro libertate}

La economía de mercado mantiene un componente libertario que la caracteriza, soportado en el principio general de libertad que sirve de base a la totalidad de las libertades constitucionales.

Es la opción en la que se tiende a favorecer y hacer prevalecer la libertad sobre la restricción: libre juego de las leyes de la oferta y la demanda en el mercado libre, concurrente con todo, con la planificación y la intervención dirigista del Estado. 


\section{REVISTA VIRTUAL VIA INVENIENDI ET IUDICANDI \\ "CAMINO DEL HALLAZGO Y DEL JUICIO"}

http://viei.usta.edu.co/ E-MAIL: revistainveniendi@usantotomas.edu.co

\section{El principio de la libre competencia}

El artículo 333 de la C.P., establece que la libre competencia económica es un derecho de todos que supone responsabilidades y que adicionalmente contempla dos obligaciones por parte del Estado, dispuestas para mantener su vigencia.

La primera establece que por mandato legal se impida la obstrucción o restricción de la libertad económica y la segunda, igualmente por mandato de ley, evitará o controlará cualquier abuso que personas o mpresas hagan de su posición dominante en el mercado.

La libre iniciativa y actividad económica constituye el ingrediente vital del sistema económico, que impregna toda la actividad de oportunidades, que delimita y limita la libertad de empresa, que hace factible el ejercicio del derecho pero a la vez impone restricciones y exigencias al sujeto empresario, en aras de proteger otros intereses generales prioritarios.

\section{Descentralización y desconcentración}

La descentralización y desconcentración, como elementos de la economía de mercado, presupone pluralidad de participantes económicos en un complejo tejido que cubre diversos ámbitos de decisión. Se hace necesario que en la ordenación del ciclo económico intervengan y tengan poder de decisión voluntaria quienes ejercen la libertad empresarial y los titulares de los diversos derechos económicos, que integran el sistema, en forma particular los consumidores y los sindicatos.

El carácter plural y descentralizado, disperso, difuso del sistema económico es regla sine qua non para garantizar la optimizad jurídico económica, de producir lo que se necesita y al precio justo, de proporcionar la satisfacción de los intereses particulares e individuales encomendados al funcionamiento de la economía en general.

La Constitución de 1991, consagra disposiciones que facilitan la participación de todos en la vida económica (art. 2), al promover y proteger las formas de asociación 


\section{REVISTA VIRTUAL VIA INVENIENDI ET IUDICANDI \\ "CAMINO DEL HALLAZGO Y DEL JUICIO"}

http://viei.usta.edu.co/E-MAIL: revistainveniendi@usantotomas.edu.co

y solidaridad de la propiedad (art. 58), a impulsar el acceso generalizado a la propiedad (art. 60), en especial la propiedad de la tierra por los trabajadores agrarios de manera progresiva (art. 64) y a estimular la participación de los trabajadores en la gestión de las empresas (art. 57). En lo que tiene que ver a la actividad empresarial, la constitución señala que los particulares pueden tomar parte en la realización de actividades que tradicionalmente venían siendo asumidas por el Estado, dentro de un modelo intervencionista (artículos 48, 365, 75 C.P.).

\section{Intervención del Estado en sus diversas modalidades}

El elemento central del principio de la economía demarcado es el de la intervención pública económica, característica intrínseca del sistema económico. ARAGÓN REYES (1995), señala que la noción de constitución económica y el nuevo modelo de Estado que con ella se representa- estado social de derecho- tiene como causa directa de alteración, el incremento de la importancia del Estado en el ámbito de las relaciones económicas. La intervención pública como característica del principio estructural de la economía de mercado, se realiza a partir de las normas generales de intervención y las normas específicas de intervención, con las primeras se habilita al Estado para ordenar y orientar la economía en general y las segundas advierten las previsiones puntuales por las cuales se atribuye competencia a las autoridades públicas para imponer reglas de dirección económica o un impacto directo sobre su funcionamiento.

\section{La unidad de mercado}

En la Constitución Colombiana la unidad de mercado no se presenta como principio expreso, pero se deduce directamente del hecho de ser un Estado Unitario, según se proclama en el artículo 1 de la Constitución. A su tiempo el artículo 150 C.P. consagra como función exclusiva del Congreso la de interpretar, reformar, crear, derogar las leyes, y el artículo 188 de la C.P. establece que el presidente de la República simboliza la unidad nacional. Adicionalmente y con referencia a la libertad económica, se consagra el artículo 333 deacuerdo al cual el Estado, por 


\section{REVISTA VIRTUAL VIA INVENIENDI ET IUDICANDI \\ "CAMINO DEL HALLAZGO Y DEL JUICIO"}

http://viei.usta.edu.co/ E-MAIL: revistainveniendi@usantotomas.edu.co

mandato legal, actuará a favor de la libertad económica y en contra del abuso de las empresas con posición dominante en el mercado nacional.

La unidad de mercado representa una unidad de objetivos y finalidades, identidad de propósitos sociales y económicos, en cuanto al mecanismo de libre circulación que asegure un desarrollo general o específico, pero en ambos casos con un impacto económico positivo generalizado. La unidad de mercado está representada, en efecto, en la identidad de ciertos objetivos, económicos generales, como de la calidad de bienes y servicios, reducción de precios y sostenibilidad del Sistema económico.

Es una finalidad ajustada a las competencias, que algunas veces se logrará a partir de las diferencias, otras a partir de la igualdad.

\section{Derechos propios de la economía de mercado}

- derecho a la libertad de empresa o económica Art. 333 C.P

- derecho de propiedad Art. 58

- derecho al trabajo Art. 25

- derecho a la libre elección de profesión u oficio Art. 26

- derechos de negociación y de adopción de medidas de conflicto colectivo Art. 55

\section{LA DIRECCIÓN DE LA ECONOMÍA COMPETENCIA EXCLUSIVA DEL ESTADO}

El Estado tiene competencia exclusiva para la regulación de los grandes parámetros o instrumentos de toda política económica a saber: Política monetaria y crediticia, política fiscal, política de precios y rentas, política laboral y sector exterior: régimen arancelario, comercio exterior, divisas, cambios y convertibilidad y a su tiempo los poderes de planificación general de la economía. El Estado mantiene un evidente poder de dirección que corresponde con la Unidad de la Nación que dispone la Constitución. 


\section{REVISTA VIRTUAL VIA INVENIENDI ET IUDICANDI}

"CAMINO DEL HALLAZGO Y DEL JUICIO"

http://viei.usta.edu.co/ E-MAIL: revistainveniendi@usantotomas.edu.co

\section{Facultades del gobierno colombiano en materia económica}

El amplio poder presidencial en Colombia, otorga facultades en el campo propiamente económico para la intervención del sector público como el privado, ya desde la constitución de 1886 se conjugaban una serie de objetivos doctrinales que presentaban modelos de justicia económica y social, a la par de diseños para el mejoramiento armónico integrado de la comunicad: Artículo. 32: "Se garantiza la libertad de empresa y la iniciativa privada dentro de los límites del bien común, pero la dirección general de la Economía estará a cargo del Estado. Este intervendrá por mandato de la ley, en la producción, distribución, utilización y consumo de os bienes y en los servicios públicos y privados, para racionalizar y planificar los servicios públicos y privados, para racionalizar y planificar la economía a fin de lograr el desarrollo integral. Intervendrá también el estado por mandato de ley, para dar pleno empleo a los recursos humanos y naturales, dentro de una política de ingresos y salarios, conforme a la cual el desarrollo económico tenga como objetivo principal la justicia social y el mejoramiento armónico e integrado de la comunidad y de las clases proletarias en particular".

Se refundieron en éste artículo, las doctrinas acerca del bien común de Santo Tomás, las de John Maynard Keines, sobre el pleno empleo, el humanismo social cristiano, con el desarrollo armónico e integrado de la comunidad, lo cual es consecuencia de una débil técnica constitucional, que permite la redacción defectuosa de textos. En la reforma de 1968, se recortaron facultades al Congreso en la ordenación del presupuesto de rentas y gastos nacionales y el principio de la planeación aplicada a la actividad económica del Estado y con ello se agigantó el poder presidencial.

El Presidente y su ministro de hacienda, tienen para entonces el manejo de la economía. El ministro de finanzas, preside las juntas del Banco de la República y del grupo de altos funcionarios que vigilan la política monetaria y cambiaria del país, designa el superintendente bancario que ejerce tutoría sobre la banca privada, nombra al director de control de cambios y de las aduanas nacionales, tiene bajo sus ordenes el manejo del presupuesto nacional de rentas y gastos, dispone de los 


\section{REVISTA VIRTUAL VIA INVENIENDI ET IUDICANDI \\ "CAMINO DEL HALLAZGO Y DEL JUICIO"}

http://viei.usta.edu.co/ E-MAIL: revistainveniendi@usantotomas.edu.co

instrumentos reguladores del comercio exterior del país y del mercado interno del café, y los impuestos son igualmente fijados por el Estado.

Carlos Lleras en 1968 culmina un proyecto de reforma constitucional, en donde se presenta la intervención del Estado más coherente con el sistema monetario, el proyecto de reforma comprende transformaciones a la concepción de las atribuciones correspondientes a las ramas ejecutiva y legislativa del poder público cuando a éste se le atribuyen importantes funciones en los campos económico y social antes vedadas a los Estados no intervencionistas. "El legislador debe limitarse a dar pautas generales al Ejecutivo, dictando únicamente la orientación política" "pertenece al gobierno desarrollar y ejecutar esa política, porque es el que cuenta con el personal y los medios técnicos requeridos para dar adecuada y oportuna respuesta a los problemas." Artículo 76.

Introducía en la Constitución el concepto de planeación, y se avanzaba en que la iniciativa de los proyectos de ley en materia económica, presupuestal y otras, fuera competencia exclusiva del gobierno. Se vigoriza la facultad ejecutiva del presidente para asumir la dirección de la economía nacional y adelantar una política planificada de desarrollo económico y social. El Conjunto de reformas a la constitución de 1886, la de 1910, 1936, 1945 y 1958, se arraigan en la idea de que el Estado requiere unidad de dirección y ejecución de la Economía, sin perjuicio de aceptar la descentralización de los servicios públicos.

El presidente quedó con más poder económico y social que antes, dueño de la maquinaria administrativa y de los cuerpos de planeación, los institutos descentralizados, bancos oficiales, crédito público, facultades tan amplias que permiten concluir que el Ejecutivo es la cabeza de la economía del país.

La democracia económica surge complementando la democracia política, se desarrolla la monopolización de la economía en Colombia siguiendo los pasos del capitalismo norteamericano. En la concentración capitalista radica el fenómeno de la economía trasformada en poder de decisión, no solo en el campo económico sino también en el campo político. 


\section{REVISTA VIRTUAL VIA INVENIENDI ET IUDICANDI \\ "CAMINO DEL HALLAZGO Y DEL JUICIO"}

http://viei.usta.edu.co/ E-MAIL: revistainveniendi@usantotomas.edu.co

En Colombia, se hizo visible el poder monopolístico en 1968 (SILVA 1977), la libre empresa, que constituía el ideal en la etapa inicial del capitalismo, tiende a desaparecer, ya no son los accionistas sino los grupos financieros los que señalan la tendencia de la producción. El poder se ha centrado en unas pocas manos, poder económico que sostiene el poder político.

¿Cómo se forma entonces la voluntad del Estado? ¿Cómo han de emplearse las fuerzas productivas de una sociedad y quien debe decidir?, La democracia se ha concebido con base en la autonomía de la voluntad del individuo en el campo político y económico, libertad individual y libertad económica.

El capitalismo y los monopolios eliminan el libre juego de la competencia reguladora del mercado, el capitalismo de monopolios sitúa en unas pocas manos la determinación de todo el proceso de extracción de materias primas, producción, selección de calidades y precios de venta en la distribución. La manera de emplearse las fuerzas productivas y quien debe decidirlo, se decide en el seno de las grandes juntas directivas de los grupos económicos. El Estado pues, no regula, sino que asiste desde lejos una operación directiva que no está en capacidad de controlar dentro de las formas jurídicas del Estado de Derecho. ¿En dónde queda entonces el poder decisorio del gobierno y el congreso en calidad de representantes de la ciudadanía? Se configura lo que se conoce como crisis del Estado Liberal, la noción de Estado de Derecho, se construye en el conjunto de voluntades, que suponían igualdad en la toma de decisión, característica vulnerada por la presencia del monopolio de capital.

Colombia llega a la reforma constitucional de 1991, con unas instituciones que no están preparadas para atender los fenómenos propios de la sociedad de masas, todos los problemas económicos y los derivados de las nuevas tecnologías deben ser asumidos y resueltos por el Presidente. Los grupos financieros dirigen el sector privado, son interlocutores del presidente, y juegan desde luego un papel preponderante en la vida política del país, comenzando por su participación en los gastos electorales. 


\section{COMPETENCIAS Y FUNCIONES EN MATERIA ECONÓMICA}

El artículo 334 de la Constitución Política de Colombia, dispone que la dirección de la economía esté a cargo del Estado, en concordancia con los artículos 150, 179, 200 y 371. De ésta lectura se determina que el Congreso Nacional, El Presidente y el Banco de la República, tienen la facultad, mediante funciones asignadas por la Constitución, para adelantar todas las actividades de dirección económica.

Cada uno de estos órganos cumple funciones separadas, independientes y autónomas, pero obligadas a colaborar armónicamente en la realización de sus fines según lo dispone el artículo 113 de la Constitución y en materia económica bajo los principios de especialización, claridad, programación integral, coherencia macroeconómica, equilibrio presupuestal y planificación.

\section{Funciones Económicas del Congreso de la República}

Dispuestas en el artículo 150 de la Constitución:

1. Aprobar el Plan Nacional de Desarrollo y de Inversiones públicas

2. Autorizar al Gobierno la celebración de contratos, negocios y enajenar bienes nacionales

3. Revestir de facultades extraordinarias al Presidente de la República, para expedir normas con fuerza de ley, cuando la necesidad lo exija o la conveniencia pública lo aconseje.

4. Establecer las rentas nacionales y fijar los gastos de la administración

5. Establecer las contribuciones fiscales y parafiscales

6. Determinar la moneda legal y su la convertibilidad

7. Aprobar o improbar los contratos o convenios celebrados por el Presidente de la República, con particulares, compañías, o entidades públicas sin previa autorización.

8. Aprobar o improbar los tratados celebrados por el gobierno con otros Estados o entidades de derecho internacional. Por medio de dichos tratados, puede el Estado, sobre bases de equidad, reciprocidad y 


\section{REVISTA VIRTUAL VIA INVENIENDI ET IUDICANDI \\ "CAMINO DEL HALLAZGO Y DEL JUICIO"}

http://viei.usta.edu.co/E-MAIL: revistainveniendi@usantotomas.edu.co

conveniencia nacional, transferir de forma excepcional ciertas atribuciones a organismos internacionales, con el objeto de promover o consolidar la integración económica con otros Estados.

9. Dictar normas sobre apropiación o adjudicación de tierras baldías

10. Dictar normas generales, señalando objetivo y criterios a los cuales se debe sujetar el gobierno para los siguientes efectos:

a. Organizar el Crédito Público

b. Regular el Comercio Exterior y señalar el régimen de cambio internacional

c. Modificar, por razones de política comercial, los aranceles y tarifas concernientes al régimen de aduanas

d. Regular la actividad financiera, bursátil, aseguradora

e. Fijar el Régimen salarial y prestacional del los empleados públicos del Congreso y de la Fuerza Pública

f. Aguar el Régimen de prestaciones sociales mínimas de los trabajadores oficiales.

11. Expedir las leyes de intervención económicas previstas en el artículo 334

12. Expedir leyes relacionadas con el Banco de la República

13. Regular el régimen de propiedad intelectual

14. Expedir el Estatuto General de la Contratación de la Administración Pública

Se evidencia que el Congreso Nacional tiene la máxima responsabilidad en los asuntos económicos del país, en la medida que se encarga de regular todos los aspectos de la actividad económica, precisar fines y alcances, establecer el límite de la libertad económica, sobre los cuales se debe basar el Gobierno, para ejecutar todas sus políticas económicas. No existe ninguna actividad o decisión económica por fuera del control institucional del Congreso.

El Ejecutivo se debe ajustar en estricto sentido a la ley en el desarrollo de sus funciones, en especial las relacionadas con el manejo económico y por los parámetros establecidos por el Legislativo, salvo los casos de Emergencia Económica, en donde el Gobierno puede actuar autónomamente y mediante su propio criterio, limitado únicamente por la Constitución. 


\section{REVISTA VIRTUAL VIA INVENIENDI ET IUDICANDI \\ "CAMINO DEL HALLAZGO Y DEL JUICIO"}

http://viei.usta.edu.co/ E-MAIL: revistainveniendi@usantotomas.edu.co

En contraste con la Constitución de 1886, la Constitución de 1991, le otorga mayor responsabilidad al Congreso de la República y le obliga a ejercer un mayor control sobre el gobierno. Frente al lo dispuesto en el artículo 150 numeral 10, el cual enviste al Presidente de facultades extraordinarias para expedir normas con fuerza de ley, cuando la necesidad lo exija, ésta facultad debe ser solicitada directamente y en forma expresa por el Gobierno y su aprobación requiere la mayoría absoluta de los miembros de las dos cámaras. El artículo 150 en su numeral 19 dispone la cláusula de competencias regula aspectos importantes de las relaciones económicas entre el Congreso y el Ejecutivo.

Por disposición de la constitución anterior a 1991, el Congreso podía, facultar al ejecutivo, para la expedición de códigos y otras leyes, delegando funciones naturales que son de su competencia, trasladando parte de su poder al Presidente, quien por ésta razón aumentó su poder en forma inusitada.

Otra característica de aumento de poder en cabeza del Presidente, la encontramos precisamente en la soltura que adquiere el Estado frente a las relaciones internacionales, en la medida en que le permite al Presidente, ejecutar de manera provisional los tratados internacionales de naturaleza económica y comercial, antes de enviarlos al Congreso para su aprobación según lo dispuesto en el artículo 224 de la Constitución.

En el Congreso de la República, funcionan siete comisiones que adelantan el trabajo parlamentario en forma especializada, lo que permite eficiencia en las preparaciones, discusiones y debates de proyectos de acto legislativo y de las leyes según lo dispone el artículo 142 de la Constitución.

Las Comisiones Parlamentarias son:

1. Comisión Primera: Estudia las reformas constitucionales, las leyes estatutarias y la organización territorial. 


\section{REVISTA VIRTUAL VIA INVENIENDI ET IUDICANDI}

"CAMINO DEL HALLAZGO Y DEL JUICIO"

http://viei.usta.edu.co/ E-MAIL: revistainveniendi@usantotomas.edu.co

2. Comisión Segunda: Aborda los asuntos de política internacional, defensa nacional, tratados públicos, comercio exterior e integración económica.

3. Comisión Tercera: Analiza lo relacionado con hacienda y crédito público, con el Banco de la República y las políticas cambiarias y de Planeación Nacional.

4. Comisión Cuarta: Encargada del Estudio de las leyes orgánicas, del presupuesto nacional, del sistema de control fiscal y del régimen de propiedad industrial

5. Comisión Quinta: Estudia las regulaciones en materia minera, de energía y de medio ambiente.

6. Comisión Sexta: abordan el tema de transportes, comunicaciones, educación, turismo y cultura

7. Comisión Séptima: Se encarga de la salud y todos los asuntos de las relaciones laborales y seguridad social.

De éste recuento puede deducirse que todas las comisiones del Congreso de la República de Colombia tienen funciones de orden económico.

\section{Funciones Económicas del Presidente de la República}

Determinadas en el artículo 189 de la Constitución, la Rama Ejecutiva del poder público cumple funciones relacionadas con el cumplimiento y la ejecución de las leyes, el Presidente en su condición de Jefe de Estado, Jefe de Gobierno, y Suprema Autoridad Administrativa, se encuentra sometido a un riguroso control por parte de los órganos de control del Estado, así como la dirección económica que ejerce.

Las reformas hechas a la constitución de 1886, que fueron quitándole funciones legislativas en materia legislativa al ejecutivo, y que fueron retomadas en la Constitución de 1991, establecieron mayores responsabilidades en cabeza del Congreso y transfirieron funciones al Banco de la República. 


\section{REVISTA VIRTUAL VIA INVENIENDI ET IUDICANDI \\ "CAMINO DEL HALLAZGO Y DEL JUICIO"}

http://viei.usta.edu.co/ E-MAIL: revistainveniendi@usantotomas.edu.co

En materia económica el Presidente tiene las siguientes funciones determinadas por la Constitución:

\section{Como Jefe de Estado:}

a. Declarar el Estado de Emergencia Económica

b. Presentar el Plan de Desarrollo y de inversiones públicas

c. Preparar y enviar a la Cámara de Representantes el proyecto de presupuesto de rentas y gastos

d. Sancionar las leyes, promulgarlas y velar por su estricto cumplimiento, así como objetarlas por inconveniencia o inconstitucionalidad

e. Ejercer potestad reglamentaria, mediante la expedición de decretos resoluciones y órdenes necesarios para a cumplida ejecución de las leyes.

\section{Como Autoridad Administrativa}

a. Designar y nombrar a cinco de los miembros de la junta directiva del Banco de la República.

b. Crear, fusionar y suprimir los empleos de la administración central y modificar la estructura de los ministerios, departamentos administrativos y establecimientos públicos según lo establecido por la ley.

c. Velar por la recaudación y administración de las rentas y caudales públicos y decretar su inversión de conformidad con la ley

d. Organizar el crédito público, regular el comercio exterior, modificar aranceles y tarifas del régimen de aduanas

e. Ejercer la inspección y vigilancia sobre instituciones de utilidad común

f. Conceder patentes de privilegio temporal a los autores de invenciones o perfeccionamientos útiles de acuerdo con la ley.

\section{Como Jefe de Gobierno}

a. El Gobierno lo conforman el Presidente de la República, los ministros del despacho, los directores de departamentos administrativos. En materia 


\section{REVISTA VIRTUAL VIA INVENIENDI ET IUDICANDI \\ "CAMINO DEL HALLAZGO Y DEL JUICIO"}

http://viei.usta.edu.co/ E-MAIL: revistainveniendi@usantotomas.edu.co

económica debe dirigir las relaciones internacionales, proponer, orientar, coordinar y ejecutar la política exterior.

b. Distribuir los negocios según su naturaleza entre los ministerios, departamentos administrativos y establecimientos públicos

c. Solicitar al Congreso de la República trámites de urgencia en los proyectos de ley.

La Presidencia de la República, para abordar los asuntos económicos, está organizada funcionalmente por el consejo de ministros, el consejo nacional de política económica y social (COMPES), por el Consejo nacional de ciencia y tecnología, y I consejo superior de comercio exterior, el departamento nacional de planeación, el departamento nacional de estadística (DANE), y los ministerios de hacienda y crédito público, desarrollo económico, agricultura, comunicaciones, minas y energía, educación, transporte, comercio exterior, trabajo, seguridad social, medio ambiente, como los de mayor influencia en materia económica.

\section{Estado de Emergencia Económica:}

Es una de las herramientas de intervención del Estado más importantes en cabeza del gobierno, para sortear las situaciones de calamidad pública que sufra la nación y que perturben o amenacen en forma grave e inminente el orden económico, social y ecológico y se usa también para corregir los errores de la política económica cometidos por el gobierno nacional.

Es precisamente la ley estatutaria 137 de 1994, la que limita, regula, define y precisa, las atribuciones que tiene el gobierno, para declarar los Estados de excepción, entre ellos el de emergencia económica, de la misma manera que establece las medidas de control y el presupuesto objetivo o supuesto del hecho que permite declarar el Estado de Emergencia.

Solo puede ser utilizada por el gobierno cuando circunstancias extraordinarias hagan imposible el mantenimiento de la normalidad, mediante los poderes ordinarios del Estado. Por esto la Corte Constitucional, debe ser estricta en el control que adelanta para no desvirtuar su aplicabilidad y efectividad y no permitir 


\section{REVISTA VIRTUAL VIA INVENIENDI ET IUDICANDI \\ "CAMINO DEL HALLAZGO Y DEL JUICIO"}

http://viei.usta.edu.co/E-MAIL: revistainveniendi@usantotomas.edu.co

que una institución que puede solucionar graves problemas, se convierta en el instrumento de los gobiernos ineptos o faltos de iniciativa para encontrar otras medidas dentro de sus facultades ordinarias.

Las Sentencias C- 004 de 1992, C-179 de 1994, C-122 de 1997, ha sustentado la posición de la Corte Constitucional en materia de presupuestos objetivos de la declaratoria de emergencia.

\section{Funciones Económicas del Banco de la República}

El Banco de la República se sometió a importantes cambios en sus funciones a partir de la Constitución de 1991. Se estructuró como uno de los organismos de dirección y control de la economía, sus funciones adquirieron por tanto rango constitucional y además se le otorgó autonomía, las decisiones que a él conciernen las toma su Junta Directiva.

La Constitución política de Colombia, dispone en su artículo 113 la estructura del Estado, es así como además de existir los órganos del poder público ejecutivo, legislativo y judicial, existen otros organismos autónomos e independientes, que colaboran con el cumplimiento de las labores y fines del Estado, funciones ejercidas en forma separada pero en colaboración armónica, entre ellos está el Banco de la República.

El Congreso de la República, por disposición del artículo 150 numeral 13, determina la moneda legal, la convertibilidad y el alcance de su poder liberatorio, en su numeral 19, le ordena regular el comercio exterior, y señalar en concordancia con la Junta Directiva del Banco de la República el régimen de cambios internacionales y en su numeral 22 dispone que al Congreso le compete expedir las leyes relacionadas con el Banco de la República y las funciones que le competen a su Junta Directiva.

La constitución de 1886 disponía que el Congreso solo definiera las bases de actuación del banco, mediante leyes de autorización al gobierno nacional, el Banco 


\section{REVISTA VIRTUAL VIA INVENIENDI ET IUDICANDI \\ "CAMINO DEL HALLAZGO Y DEL JUICIO"}

http://viei.usta.edu.co/E-MAIL: revistainveniendi@usantotomas.edu.co

funcionaba como un agregado del Gobierno. En la Constitución de 1991, el Banco de la República deja de ser solo un banco emisor, bajo la potestad interventora del ejecutivo y pasa a cumplir funciones de Banca Central, con atribuciones constitucionales de poder decisorio y autónomo y responsable sobre los instrumentos de control monetario, cambiario, crediticio, con independencia institucional.

La emisión de la moneda es para el Estado, una de las funciones básicas y de carácter institucional que representa la soberanía y constituye la base del sistema monetario como tal se ha transformado a través del tiempo, tras la necesidad de las naciones de contar con un medio idóneo para administrar los recaudos de dinero, para establecer el sistema crediticio y de manera especial para efectuar la emisión de la moneda, que permita ordenar la estructura económica del país. Precisamente para cumplir esta importante misión se crea el Banco de la República que resulta luego de años de evolución de la institución que en principio se creara para emitir la moneda. (Leguizamón 2001)

\section{Funciones del Banco de la República y de su Junta Directiva}

Le corresponde la regulación del dinero, los artículos 371 y 373 de la Constitución establece como funciones básicas del Banco de la República:

1. Regular la moneda legal

2. Regular los cambios internacionales y el crédito

3. Emitir la moneda legal

4. Administrar las reservas internacionales

5. Ser prestamista de última instancia y banquero de los establecimientos de crédito

6. Servir como agente fiscal del gobierno

7. El Estado a través del Banco de la República velará por el mantenimiento de la capacidad adquisitiva de la moneda

El artículo 372 dispone que la Junta Directiva del Banco de la República: 


\section{REVISTA VIRTUAL VIA INVENIENDI ET IUDICANDI \\ "CAMINO DEL HALLAZGO Y DEL JUICIO"}

http://viei.usta.edu.co/ E-MAIL: revistainveniendi@usantotomas.edu.co

1. será la autoridad monetaria, cambiaria y crediticia

2. tendrá a su cargo la dirección y la ejecución de las funciones del banco

3. tendrá la dirección de las políticas económicas

El Banco de la República y su Junta Directiva se convierten, en uno de los órganos de dirección económica del Estado, con notable influencia en el desarrollo y crecimiento de la economía. Sin embargo actúa coordinadamente con la política general, ordenada por el ejecutivo y el legislativo.

Se concluye que la estructura formal de la Constitución no responde a la estructura real. La primera presenta sometimiento de los poderes públicos a la constitución y a la ley, desempeño de la facultad legislativa y de control político por las dos cámaras del Congreso, Régimen económico de empresa privada y libre competencia, libertad de información; la segunda, la estructura real responde a la elección interferida por las cuotas de participación de los grandes y más importantes grupos económicos y financieros en las campañas electorales, elasticidad en la interpretación constitucional y laxitud para su reforma, abandono de la facultad legislativa y de control político del ejecutivo por el Congreso como expresión de solidaridad política, abolición de la libre competencia económica y aparición de los grupos financieros como directores y dueños del sector privado, y finalmente el control financiero ejercido por los mismos grupos económicos.

\section{CRISIS DEL ESTADO SOCIAL}

Su ocurrencia, fundada en cifras, en la revisión de resultados, en el cambio de la sociedad, en la ubicación en el mercado de las más de las expectativas del bienestar social, y también por su puesto, en el giro ideológico importante de las fuerzas políticas públicas ordenadas por los Estados, a veces a motu propio, a veces bajo el auspicio de la Comunidad Económica Europea, o la presión del Banco Mundial y el FMI, y las instancias supranacionales.

Debe en principio establecerse una diferencia conceptual entre el Estado Social y el Estado Bienestar, providencial o asistencial, y a partir de ésta distinción, señalar 


\section{REVISTA VIRTUAL VIA INVENIENDI ET IUDICANDI \\ "CAMINO DEL HALLAZGO Y DEL JUICIO"}

http://viei.usta.edu.co/ E-MAIL: revistainveniendi@usantotomas.edu.co

que no es la reducción del Estado Social la que defienden los liberales y nuevos estadistas sino la reducción del Estado Bienestar.

La tendencia socializante se conecta con la finalidad de favorecer un mínimo de igualdad material, o reducir las diferencias económico sociales, que el sistema de economía libre incrementa o al menos no resuelve, con mayor o menor intervención directa o indirecta del Estado en la economía o en la prestación de los servicios, pero sobre todo con su deber y responsabilidad de orientador y corrector, con respecto a los derechos económicos y sociales.

Es en concreto, el modus operandi de éste tipo ideológico de Estado es lo que debe trasformarse, no es la sustancia del estado Social. la crisis ha sido inducida por la forma en la que el poder público ha incidido y decidido sobre el factor económico y social y sobre la aplicación generalizada del modelo de intervencionista.

El Estado no se encuentra llamado a servir a intereses particulares ni a gestionar de manera eficiente y omnipotente un número cada vez más creciente de servicios sociales. Por esta razón, el modelo de Estado Social que ha dado lugar a un modelo de gestión pública de servicios sociales, se encuentra hoy en un proceso de revisión.

Los efectos negativos que ha traído consigo la puesta en marcha del modelo de Estado Social como prestador de servicios económicos y sociales, distribuidor de rentas y primer empresario del país, han sido entre otras:

1. El crecimiento del sector público

2. El incremento del gasto público así como la presión fiscal sobre los contribuyentes

3. La Ineficiencia en la prestación de los servicios, debida a la burocratización de los agentes llamados a prestar los servicios.

4. La actividad del Estado sirve a intereses particulares, sectoriales, o de los partidos políticos y no posee la capacidad suficiente para gestionar 


\section{REVISTA VIRTUAL VIA INVENIENDI ET IUDICANDI \\ "CAMINO DEL HALLAZGO Y DEL JUICIO"}

http://viei.usta.edu.co/ E-MAIL: revistainveniendi@usantotomas.edu.co

eficientemente el número creciente de servicios sociales asumidos por el poder público.

El Estado Social, desde el punto de vista jurídico -político, se transforma lentamente en Estado dominador (ARIÑO2007). Por una parte, el Estado de Derecho garantizaba libertades, derechos fundamentales, constituyendo un excelente sistema de defensa frente a las intervenciones del Estado, pero no garantizaba la sanidad, la educación, el trabajo, etc. En el Estado Social, el Ciudadano vive del Estado, éste es su benefactor. El Estado le ofrece bienestar a cambio de su libertad, lo cual suscita deficiencias en el desarrollo y sin duda de atraso social, el Estado se convierte en dominador. y el ciudadano al momento de participar en elecciones se orienta en función de su interés particular, en razón de los beneficios que pretenda del Estado.

\section{REFORMA DEL ESTADO SOCIAL}

El Estado Social debe reformarse en sus tareas. En concreto debe cambiar el modelo de gestión de los servicios sociales

- El Estado está para perdurar, debe para ello cumplir eficientemente sus funciones, respetando la legalidad y la libertad de los ciudadanos y evitando la invasión y manipulación de lo colectivo de manera directa o a través de los partidos políticos. No se discuten los resultados de bienestar alcanzados hasta ahora, gracias al Estado social pero se plantea una adecuación administrativa que permita a través de empresas privadas y organizaciones no gubernamentales, capaces de asumir con mayor flexibilidad, eficacia y calidad, las necesidades sociales, incluso con financiación estatal o mixta.

- Es necesaria una transformación en las tareas del Estado. Pasar de la gestión a la regulación, asumir un papel de regulador, árbitro, supervisor, fomentador de la iniciativa privada, creador y defensor del mercado y éstas tendencias exigen transformación es en el aparato del Estado. 


\section{REVISTA VIRTUAL VIA INVENIENDI ET IUDICANDI \\ "CAMINO DEL HALLAZGO Y DEL JUICIO"}

http://viei.usta.edu.co/ E-MAIL: revistainveniendi@usantotomas.edu.co

- No se deja de lado que la misión estatal de defensa de la libertad y de la iniciativa individual, es concurrente con su deber de hacer efectiva la solidaridad social, pero eficaz, lejos del altruismo burocratizado que genera altos costos y deficiente prestación de los servicios. Debe buscarse una solidaridad que no alimente la mediocridad y la ley del menor esfuerzo, que conlleva solo al desaceleramiento en el desarrollo de un país.

El modelo de prestación de servicios sociales tenderá a:

1. Identificar quien necesita realmente el servicio

2. favorecer la competencia entre los prestadores de servicios a partir de la libertad de elección y el control estatal sobre dichos prestadores.

Los problemas de gobierno en el contexto de la globalización, no se limitan ya a las fronteras del Estado territorial. Algunas problemáticas precisan respuestas globales, unilaterales o multilaterales. Los gobiernos no pueden actuar de manera independiente, sin contar con actores como los organismos internacionales, el mercado y la sociedad civil, que conducen a la estructuración de un gobierno "multiniveles" con una estructura en red, que favorece las respuestas globales, a través de redes trasnacionales (RUBIO 2007).

La dinámica del fenómeno político encarna una serie de cambios que pueden ser vistos, unos como evolutivos y otros como revolucionarios. Todos se orientan a atender la necesidad de armonía y justicia social. Sin embargo, debe tenerse en cuenta que nuestra historia refleja las fallas de una u otra ideología, que puede deberse al deseo de concentrar mayor poder de quienes acceden, a él, por oposición al deseo de libertad de quienes se encuentran sometidos a cualquier ejercicio de poder, como respuesta natural propia del ser humano.

Se debe trabajar en el fortalecimiento institucional y estratégico del poder público y de la administración que favorezca la dignidad humana, la solidaridad social, la prosperidad colectiva y la paz. 


\section{REVISTA VIRTUAL VIA INVENIENDI ET IUDICANDI}

"CAMINO DEL HALLAZGO Y DEL JUICIO"

http://viei.usta.edu.co/ E-MAIL: revistainveniendi@usantotomas.edu.co

La labor del Estado debe concentrarse en propiciar un desarrollo institucional, producto de los cambios experimentados en distintos niveles con ocasión a la integración económica, un proceso desarrollado en la dinámica de cada país, atendiendo a sus particularidades políticas, sociales y económicas, y gran parte de la importancia de éste proceso y su éxito tiene que ver con la no implantación de modelos que estén en contextos muy diferentes a los propios, y ser pertinentes al momentos de crear teniendo en cuenta la necesidad de optimizar los procesos en el momento de organizar la estructura de las instituciones.

Redimensionar las instituciones implica la necesidad de revisar la concepción del Estado, la interacción económica y la economía de mercado obliga revisar la obligatoria transformación en la articulación institucional del Estado, y la naturaleza y transformación de la misma. (ANZOLA 2005)

Surge la necesidad del Estado de asumir su papel en las relaciones supranacionales y trasnacionales, al igual que el reconocimiento de decisiones supranacionales que deben ser adoptadas por ellos, siendo ésta una de las características del nuevo orden mundial.

Se transforma el orden constitucional, la Unión Europea adelanta un proceso para a través de la Convención Europea, redactar la Constitución Europea que tiene como propósito no solo estableciendo las directrices para las relaciones económicas entre los Estados miembros sino si no que comprende temas como los derechos fundamentales, distribución de competencias, coordinación de políticas económicas y de empleo, la política exterior y de seguridad común, así como las instituciones rectoras, incluyendo un tribunal de justicia con competencia de control constitucional.

Tradicionalmente era el gobierno el que a través de las autoridades estatales el agente clave o central, ahora el concepto gobierno comprende una complejidad de actores, además de las tradicionales autoridades públicas está la sociedad civil, el sector privado, las instituciones internacionales bilaterales y multilaterales. 


\section{REVISTA VIRTUAL VIA INVENIENDI ET IUDICANDI \\ "CAMINO DEL HALLAZGO Y DEL JUICIO"}

http://viei.usta.edu.co/ E-MAIL: revistainveniendi@usantotomas.edu.co

La interacción económica y la economía de mercado, promueve formas de gobierno que suscita la asignación de tareas públicas al sector privado y donde la actividad del Estado se enfoca hacia la regulación de los mercados diseñando y asegurando un marco jurídico propicio, así como una administración y justicia eficiente y transparente.

Es por tanto deber del Estado, asegurara que el mercado se desarrolle en el marco de códigos de ética con carácter vinculante para los agentes económicos , promueva la protección del medio ambiente y garantice los derechos sociales, generando formas de gobierno y administración de lo público, yendo más allá de lo concebido tradicionalmente.

\section{Estado fuerte}

El Estado es fuerte en la medida en que asume los procesos de gestión y legitimación en el espacio nacional, de las exigencias del capitalismo global, no puede hablarse de una crisis del Estado, sino de la crisis de un determinado Estado (SANTOS 2003).

La debilidad del Estado se presenta como resultado no del proceso de le globalización de la economía, si no de un proceso político que pretende conferir al Estado un tipo de fuerza que intenta ajustarse alas políticas de capitalismo global pero que en el marco de la corrupción es difícil adelantar.

Las ideas neoliberales pretendieron presentar la idea de la reducción del estado a su mínima expresión ante la imposibilidad de su reforma, es decir, el Estado no podría adoptar estructuras que permitiesen una razonada lógica mercantil, así que lo que asegura según éste argumento el funcionamiento del mercado es la reducción del Estado.

La corrupción que llevó a la quiebra a algunos países en vía de desarrollo, llevó a la idea de necesidad de fortalecer el Estado, y debía ser objeto de reforma reflejo de esto el Estado de bienestar o el Estado desarrollista, lo cual conduce a la 


\section{REVISTA VIRTUAL VIA INVENIENDI ET IUDICANDI \\ "CAMINO DEL HALLAZGO Y DEL JUICIO"}

http://viei.usta.edu.co/ E-MAIL: revistainveniendi@usantotomas.edu.co

posibilidad de reformar la naturaleza del estado obedeciendo a los parámetros racionales de la lógica del mercado.

El Estado mínimo e irreformable se encontró siempre dominado por los intereses del capitalismo global, la edad de oro del neoliberalismo. Sin embargo el Estado conserva su carácter represivo, su protagonismo en los procesos de regionalización supranacional y de liberalización de la economía mundial, su función de fomento y protección de las empresas privadas que ejercen funciones públicas, esto no está en crisis. Lo que verdaderamente aparece en crisis es la función de las intermediaciones no mercantiles entre ciudadanos, fundadas en el equilibrio de la hegemonía y la confianza por un lado y estrategias de acumulación que son las dominantes por otro lado.

Estas funciones son dada vez más importantes y hacen del Estado un Estado Fuerte, por tanto el Estado es reformable y puede fortalecerse en el marco de su función integradora mundial reorganizando sus instituciones, regulando la actividad comercial y ejercitando sus mecanismos interventores en procura del bienestar general y el desarrollo sostenible del país.

\section{El Estado colombiano}

El país afronta una crisis económica mundial, con unos problemas de pobreza y confrontaciones institucionales, el desorden institucional ha generado una grave e inerte inflación normativa. El Estado ha hecho frente por años a una situación política conflictiva, desgastada en el marco de la violencia interna, y se ve obligado a presentarse en el ámbito global menos centralista y más globalizado con necesidad de mirar hacia las regiones. Los problemas son de tipo estructural y de corrupción y es deber del Congreso y el Gobierno entrar a solucionarlos. Deben revisarse los problemas de ejecución y gerencia en lo relacionado con infraestructura, revisar el problema agrario colombiano, sabiendo que en el agro se encuentra el futuro de las exportaciones, y que es clara la necesidad de tratar el tema en salud y pensiones como punto mínimo de reflexión a mediano plazo. 


\section{REVISTA VIRTUAL VIA INVENIENDI ET IUDICANDI \\ "CAMINO DEL HALLAZGO Y DEL JUICIO"}

http://viei.usta.edu.co/ E-MAIL: revistainveniendi@usantotomas.edu.co

\section{CONCLUSIONES}

1. La actividad económica posibilita una amplitud de alternativas que den mayor o menor cabida al intervencionismo estatal, por tanto no se puede hablar de un modelo económico rígido consagrado en la Constitución.

2. Existen lineamientos que perfilan el sistema económico, que se deducen de la interpretación conjunta de los derechos fundamentales reconocidos al ciudadano y de las posibilidades de intervención establecidas por el Estado.

3. La Libertad de Empresa, ejercida en el marco de una economía de mercado, conlleva a la libre y leal competencia económica. La acción estatal se encamina a garantizar la defensa del mercado, la libre y leal competencia económica, sin perjuicio de intervenir en caso de abuso de posiciones dominantes en el mercado que vulneren el derecho a la igualdad y demás derechos fundamentales.

4. La propiedad solo puede limitarse en su contenido, por vía de ley formal, en la que se especificará, la finalidad social a que esté llamada.

5. La intervención del Estado se valora en la medida en que promueve la igualdad real y efectiva entre los ciudadanos, sin perjuicio de los derechos de todo tipo reconocidos y garantizados en la Constitución.

6. En la medida en que el ordenamiento superior tenga fuerza normativa y reconozca derechos constitucionales, impone límites a la política económica.

7. La Constitución no es una norma jurídica común, constituye un intento de diseño configurador de la sociedad, se formula en términos ambiguos, para que puedan albergar diferentes alternativas políticas. (ARIÑO ORTIZ 2003)

8. La democracia se tornó un mercado (SANTOS 2002), y a ello se debe la corrupción. La democracia actual es de muy baja intensidad, una sociedad solo es democrática cuando nadie es tan pobre para tener que venderse ni nadie tan rico como para poder comprar a alguien (ROUSSEAU 1988).

9. La sociedad Civil es una concepción basada en la solidaridad, el voluntariado y la reciprocidad (SANTOS 2002), "en donde las víctimas de la globalización dominante se transformen en protagonistas de su propia liberación". 


\section{REVISTA VIRTUAL VIA INVENIENDI ET IUDICANDI \\ "CAMINO DEL HALLAZGO Y DEL JUICIO"}

http://viei.usta.edu.co/E-MAIL: revistainveniendi@usantotomas.edu.co

10. Es una sociedad civil que sabe que el Estado no ha perdido su valor y su poder, solo que, está diseccionando sus actos a la protección de las empresas y no a los ciudadanos. La trampa de la globalización es crear el convencimiento de que el Estado se encuentra derrotado, y la sociedad civil debe encaminar sus acciones a estimular el papel del Estado en procura del bienestar de la colectividad.

11. La Constitución de 1991 de Colombia, es una constitución normativa valorativa de constitucionalismo social, en la medida que no solo reconoce derechos liberales, sino también derechos sociales y les da fuerza normativa, pero es una Constitución abierta, porque admite políticas económicas muy diversas para alcanzar esos derechos sociales.

12. Los problemas que afronta el Estado colombiano son de tipo estructural y de corrupción y es deber del Congreso y el Gobierno entrar a solucionarlos. Deben revisarse los problemas de ejecución y gerencia en lo relacionado con infraestructura, revisar el problema agrario colombiano, sabiendo que en el agro se encuentra el futuro de las exportaciones, y que es clara la necesidad de tratar el tema en salud.

13. El Estado es reformable y puede fortalecerse en el marco de su función integradora mundial reorganizando sus instituciones, regulando la actividad comercial y ejercitando sus mecanismos interventores en procura del bienestar general y el desarrollo sostenible del país.

\section{BIBLIOGRAFÍA}

ARAGÓN REYES Manuel (1995). Libertades económicas y Estado Social. Madrid, McGraw-Hill, 1995.

ARIÑO ORTIZ Gaspar (1999). Principios de Derecho Público Económico. Ed. U. Externado. Colombia 1999

COLCLOUHG Christofer (1994). Estados o Mercados El Neoliberalismo y el debate sobre las políticas de desarrollo. Ed. Fondo de Cultura Económica. Mexico D.F. 


\section{REVISTA VIRTUAL VIA INVENIENDI ET IUDICANDI \\ "CAMINO DEL HALLAZGO Y DEL JUICIO"}

http://viei.usta.edu.co/E-MAIL: revistainveniendi@usantotomas.edu.co

CONSTITUCIÓN POLÍTICA DE COLOMBIA 1991

CORREA HENAO Magdalena (2008). Libertad de Empresa en el Estado Social de Derecho. Ed. U Externado. Colombia 2008.

DE SOUSA SANTOS Boaventura. (2002). La Globalización del Derecho. Ed. Universidad Nacional de Colombia. Bogotá.

GARCÍA PELAYO Manuel (1985). Las trasformaciones del Estado, Madrid, Alianza. 1985

LEGUIZAMÓN ACOSTA William (2001). Introducción al análisis de la Economía Política Colombiana. Ed. Ibañez. Bogotá

MONTENEGRO Walter (1997). Introducción a las doctrinas político-económicas. Fondo de Cultura Económica. Colombia 1997

REICH Norbert (1985). Mercado y Derecho. Barcelona. Ariel1985.

RUBIO Rafael (2007) LOS CIUDADANOS ¿PROTAGONISTAS DE LA GLOBALIZACIÓN?. En : La Globalización del Derecho. Editor Gonzalo Ramírez Cleves. Ed. U. Externado 2007.

UPRIMNY Rodrigo (2007). Abierta pero no neutra: Constitución y modelo económico en Colombia. En: Memorias del conversatorio "Diálogo entre abogados y economistas sobre la Constitución en el aspecto económico". Ministerio de Hacienda y Crédito Público. 2007

\section{SENTENCIAS:}

Sentencia T-505 de 1992

Sentencia T-542 de 1992 


\section{REVISTA VIRTUAL VIA INVENIENDI ET IUDICANDI}

"CAMINO DEL HALLAZGO Y DEL JUICIO"

http://viei.usta.edu.co/ E-MAIL: revistainveniendi@usantotomas.edu.co

Sentencia C- 074 DE 1993

Sentencia T-401 de 1994

Sentencia C-535 de 1997

Sentencia T-067 de 1998

Sentencia SU-337 DE 1999 